OPEN ACCESS

Edited by:

Marco Mezzadri,

Università degli Studi di Parma, Italy

Reviewed by:

Patricia Taylor

Humanitas Università, Italy

Arturo Hernandez,

University of Houston, United States

*Correspondence:

Julia Festman

julia.festman@ph-tirol.ac.at

Specialty section:

This article was submitted to

Language Sciences,

a section of the journal

Frontiers in Communication

Received: 16 March 2018

Accepted: 07 June 2018

Published: 03 July 2018

Citation:

Festman J (2018) Vocabulary Gains of Mono- and Multilingual Learners in a Linguistically Diverse Setting: Results From a German-English Intervention With Inclusion of Home Languages.

Front. Commun. 3:26.

doi: 10.3389/fcomm.2018.00026

\section{Vocabulary Gains of Mono- and Multilingual Learners in a Linguistically Diverse Setting: Results From a German-English Intervention With Inclusion of Home Languages}

\author{
Julia Festman* \\ Institute of Primary and Secondary Education, Pedagogical University Tyrol, Innsbruck, Austria
}

Today, group settings (e.g., in kindergarten) are more linguistically diverse than ever. However, concepts in language acquisition only rarely include this fact. This paper reports on the effects of a language intervention which is based on a concept specifically designed for linguistically diverse settings ("PROgramme for $\mathrm{BI}$ - and MUltilingual Children"; Festman and Rinker, 2014). The implementation of the programme and its outcomes are described with the example of a German-English-immersion kindergarten, which was in fact plurilingual. We aimed at supporting children's acquisition of these two languages in parallel with inclusion of their home languages. Overall, 52 (mono-, bi-, and trilingual) children took part in the intervention, but data will only be presented for those children ( $n=22 ; 12$ male; mean age 3;9 years, SD 0.526) who also participated in the evaluation. Two weeks before ( $(\mathrm{T} 1)$ and 12 weeks after (T2) intense intervention, we administered a word production and word comprehension test (picture naming) both in German and English. Furthermore, parents filled out a questionnaire on language background and use; after the intervention, they provided feedback on the programme (their impressions and observations, etc.). Paired $t$-tests showed that the intervention noticeably boosted all children's word learning (all gains from T1 to T2 were significant with $p<0.001$ for both languages and both production and comprehension). With a head start in German (i.e., at T1 significantly higher scores in German comprehension and production), the monolingual German participants $(n=11)$ reached significantly higher scores in German at T2 compared to their peers. The international group $(n=11)$ had significantly larger gains in German than their monolingual peers $(p=0.037$ for production; $p=0.015$ for comprehension), but not in English. We conclude that with the help of this structured programme and due to plurilingual experiences, minority children were able to improve language skills in two newly-learned languages, 
whereas the monolingual children were still consolidating knowledge in their first language and focused on the acquisition of the new language. Parents' responses described the positive impact of the programme on their children's language learning interest and their own.

Keywords: fast-mapping, intervention, language acquisition, children, kindergarten, lexicon

\section{INTRODUCTION}

Acquisition of a first language is considered to be a natural process. It is not systematic or planned, and takes a long time. In the case of typically-developing children, it usually leads to perfect mastery of the language to be learned (Klein and Dimroth, 2003), if rich input is provided. It is based on dayby-day communication and interaction with speakers of that language.

Even learning two languages in parallel is by no means unusual today. Many babies are born into families in which the parents use more than one language at home. Some caregivers who wish to raise their child with two languages follow language teaching principles such as the "one parentone language" approach (Ronjat, 1913), while others use more situation- or context-dependent language choices for family communication (see Festman et al., 2017 for an overview). Acquisition of several languages within the family context necessitates sustained interaction in those languages between family members with space for individual exchange, attention to the child, and highly intuitive parental guidance in the natural language acquisition process (Langdon, 2011).

Learning a language at home is implicit (see Paradis, 2004). Other language learning contexts, however, may be more explicit and involve teaching methods and language acquisition through "formal" instruction. This more "formal" language acquisition approach is often used in group settings such as language courses in kindergarten, foreign language classes at school, etc. It is usually based on text-books, didactic materials, and pedagogical teaching. Rules are learned explicitly, something which is commonly considered to involve a conscious effort (Schrauf, 2008).

Today, many kindergartens offer immersion programmes. They thereby support the recognition of the increasing importance of foreign language learning (Council of Europe, 2001) and meet the parental wish for bilingual education, in particular the early acquisition of English. Bilingual education is used as a broad umbrella term (May, 2008), with huge differences in implementing the bilingual approach in terms of time and instruction per language, starting point, qualification of teachers, subjects and teaching methodology, etc. (see Cummins, 2009 for an overview). There are only few studies which focused on language development in immersion contexts at the kindergarten level. Some of them investigated the effect of bilingual immersion on the L1-development in minority-language children (e.g. Winsler et al., 1999; Leseman, 2000) or in majority-language children (Steinlen et al., 2010). Others reported on L2-acquisition of majority-language children (e.g., Barik and Swain, 1975; Schelletter and Ramsey, 2010).

Due to the world-wide acceleration of globalization and migration, learning settings seem to be more heterogeneous than ever before. The same contextual factors relevant for school settings (Kuhs, 2008) also play a role in the kindergarten context. Children do not only differ in terms of socio-economic background, parental level of education and parents' educational aspiration for themselves and their children, experiences with and knowledge of literacy, experiences of migration or relocation. There are also differences in language background and proficiency in their languages, frequency of contact with the language of their speech environment, and how closely their first language is related to the language in their speech environment (kindergarten, school, etc.). Individual factors such as memory, self-esteem, motivation, aptitude, learning styles, learning strategies, empathy, introversion, and extraversion are known to influence the rate of acquisition and learner success (see Dörnyei, 2005; see Dewaele, 2010 for the relation between multilingualism and emotions).

In the present paper, we present one example for current diversity in a kindergarten which may illustrate the heterogeneous composition of language background. The group attending the kindergarten consisted of three sub-groups: (i) children born in Germany with German as their home language; (ii) children born in Germany with home languages other than German and with a history of migration in the family [e.g., the (grand)parent(s) migrated to Germany]; and (iii) children born in other countries and raised with another language than German.

In the example described in the present study, attending the German-English immersion kindergarten had different consequences for the three sub-groups. Children speaking German (the majority-language) were immersed in English while still undergoing language acquisition processes and refinement in German, their first language. In the long run, for this first group of children, immersion is expected to result in additive bilingualism. Immersion kindergartens commonly focus on majority-language speaking children who learn one additional language.

But the challenge is different for minority-language children. Those born in Germany may have been exposed to German already to some extent. As soon as they entered the immersion kindergarten, they were immersed in German and English. They could improve their German skills and concentrate on the acquisition of English. Other children born outside of Germany, however, had grown up with another language abroad which was still spoken in their international families in the 
new context (i.e., living and working in Germany). But what if these minority-language-speaking children are supposed to learn two entirely new languages in parallel in kindergarten? For such parallel acquisition of two new languages (in addition to their home language acquisition process), there seems to be a lack of methodological approach ${ }^{1}$. The international children with home languages such as Japanese, Mandarin, Hebrew, Polish, etc. were faced with double immersion in German as well as in English. These children had no background in any of these two languages. At the same time they were still undergoing language acquisition processes and refinement of their first language. Consequently, their language background situation required the acquisition of two new languages in parallel in a group setting. Double immersion has been implemented in the school (but not in the kindergarten) context already for quite a while, as Genesee (1995) reported on English-speaking school children who received double immersion in French and Hebrew in Montreal. English was introduced as a school subject only later, and the school subjects (mathematics, arts, science, religious, social and cultural studies, history, etc.) were divided between the two other immersion languages.

The question that needs to be asked here is whether a kindergarten could be prepared conceptually for such a challenge and opportunity. The concept was to follow the one personone language principle with the following implementation: four kindergarten educators, who used exclusively their first language (German), and one native speaker of English (unfortunately with no background in being an educator) and no knowledge of German were taking care of the children, all in one large group. Therefore, given the number of educators, most communication was in German, and all children who wanted to avoid immersion in English could do that.

Initial observations revealed that the kindergarten team followed a model of submersion in both languages, meaning that there was no targeted support for the children in any of the languages. The educators of that kindergarten seemed insecure in light of the obvious multidimensional heterogeneity in this group of children mostly left them to play amongst themselves. There were hardly any joint-attention activities between kindergarten educators and children. Unfortunately, the educators did not provide many opportunities for interaction with the children, something which implied that they could not act as language models and provide rich input. It was rather silent in the kindergarten. In an interview (see the transcript of the interview, Stoll, 2012, p. 63), the English caretaker explained that the children did not understand him, that he only spoke to them in English, but that he always needed another educator to translate or explain to the children what he had said.

\section{The Concept}

It became clear that a new language teaching concept was urgently needed (see Festman and Rinker, 2014 for a first general overview of the concept), which would meet the children's needs

${ }^{1}$ We use the term "home languages" (see Conteh, 2015) as we focus on home exposure for language learning. in such highly heterogeneous and linguistically diverse contexts. The aim of the concept had to be the functional use of two specific languages (e.g., German and English). The target groups were young majority as well as minority children, and the target age range was largely between the age of 3-6 (i.e., prior to language teaching possibilities in school education). To that end, several key principles were integrated into "ProBiMuc" ("PROgramme for BI- and MUltilingual Children") and developed in a unique way to provide a concept suitable for the kindergarten context. This concept will be described in more detail in the following section.

Methodologically, we used an age-appropriate teaching approach which was playful and included games, movement and gestures, repetition, and music. Combining multiple sensory input has a high potential for learning languages (Böttger, 2016 , p. 117), because words can be memorized faster and retrieved more easily if the word is well differentiated in its semantic representation. Böttger explained in detail how multiple sensory input and stimulation enhanced consolidation, enriched representations in memory and made retrieval easier due to several ways one could recall a word. Repetition of the same or similar stimuli promoted consolidation of knowledge and was, according to Böttger (2016, pp. 116, 151), the key to successful language learning, which necessitated both time and training. Therefore, we contextualized the new words and provided interactive environments to support the children's language learning (e.g., by the frequent use of concrete contextual referents such as visuals, graphics, and realia). Together with the children, we negotiated the meaning of the new words, including their home language as well. We used gestures when introducing new words as well as a song about the colors of the world (see Zaiser, 2005 for the effect of music on early language learning). Children quickly understood the meaning of the new words, had fun when repeating the new vocabulary, experienced the sound of the words and did not get tired of actively using the newly learned words.

Our target words were not taught in isolation but rather in continuous speech to provide context, a key factor for successful language learning (see De Groot, 2011). By combining word and movement we helped children to explicitly detect word boundaries as it is difficult to segment the speech stream into words (in particular at the very beginning of acquiring a new language). Moreover, intentional vocabulary learning was framed in diverse activities which deliberately aimed at committing lexical information to memory (see De Groot, 2011) and at the same time fostered a process for language acquisition which was as naturalistic as possible, including diverse contexts such as play, stories, interaction, etc. (Langdon, 2011).

Tracy (2008) suggested that apart from natural immersion in the German-speaking language environment, children with migration background urgently needed focused and specific input when learning German. What has been suggested for the acquisition of one new language might be indispensable when having to acquire two. Thus, content-wise, we chose specific, basic vocabulary and useful chunks relevant for the children's day-by-day kindergarten communications, with peers and with each of the kindergarten educators. Since we realized 
that the English caretaker was sometimes alone with the children for the breakfast, we chose some crucial words to make the communication possible and easier. We planned a session on dishes and cutlery and included the following words: a cup, a glass, a plate, a spoon, a fork. Or because some children (who grew up in China, Japan, Israel, etc.) were more familiar with warmer temperatures, we focused on words such as jacket, trousers, scarf, hat, socks and shoes when it turned autumn. The goal was to provide the linguistic material for immediate use after the sessions and thereby to support the comprehension and production of these words as well as outside of the programme sessions. As such, we aimed for a fruitful application of the factor "importance-relevance-usefulness" which is known to be crucial for successful, motivated language learning, as the limbic system categorizes newly-perceived linguistic input according to these dimensions and links it to positive emotions (Böttger, 2016, p. 150).

Here, time comes into play as it is a key component for successful language learning (Böttger, 2016, p. 132). While early acquisition of the first language in the home context is often thought to consist of non-stop language input the acquisition of additional languages is probably more dependent on structured input in formal teaching contexts, as there is less contact time with each language. We tried to combine these two ends of the learning context continuum (informal at home-formal at school). We followed a structured idea of the relevant topics to be in the focus of consecutive sessions with the children but provided moments of playful input and natural language production. Moreover, we wanted to provide the children time to process the language input.

We wanted to support children's active attempts at sorting out information from the speech stream, to make them "better able to understand," since "without understanding, learning will not take place" (Gass and Glew, 2008, p. 281). Therefore, we used modified input characterized by slower speech rate, very clear articulation (providing a model to imitate), simple syntax, the use of high frequency vocabulary, few idioms, and less slang (Gass and Glew, 2008).

We did not strictly follow the "one person-one language" approach. Instead, we wanted to provide a positive example for, i.e., by reacting flexibly in terms of language choice when linguistic contexts and situations change (Tracy, 2008). The use of German and English was specifically linked to the involvement of two cuddly toys: Probimuc, a German "speaking" frog who wanted to learn English to be able to talk to his friend Amy, an English "speaking" bear. With the help of the cuddly toys, we explained the concepts of monolingualism to the children, defining it as language knowledge in only one language (for which Amy served as an example), the need to sometimes translate, and the possibility of learning and using several languages (with Probimuc as example). Moreover, we used the cuddly toys for scaffolding in each language, and they were our main characters in short theater acts, etc. Very shy children were drawn to these toys which initiated a feeling of confidence, and they slowly lost their reluctance to communicate. Together with Probimuc, they learned new languages.
Additionally, this concept aimed at developing and fostering a positive self-image. The ability to speak in a new language does not only rely on language components, such as pronunciation, prosody and intonation, vocabulary and grammar knowledge, syntactic knowledge and pragmatic abilities, but it needs the selfconfidence of the language producer (Böttger, 2016). Therefore, repetition and integrated training were key elements of the intervention since these are known to provide confidence for the speaker (Böttger, 2016). Children were motivated and encouraged to produce language output in order to develop fluency and automaticity of processing two target languages (Gass and Glew, 2008, p. 287). Scaffolding helped the children to refine their knowledge step by step.

Another very crucial component of the programme was the use of worksheets (for an example, see Figure 1). They comprised the crucial vocabulary of the session in usually 5-6 words or chunks. We included the names of the pictures/objects/actions in German and English with which the children had been familiarized during the session (see Figure 1). Additionally, we put an empty line below the German and English names for the parents to fill in the name of the word in their home language. That way we clearly signaled that we wanted the home languages to be part of the acquisition process in the programme and valued the home languages in the most concrete way-in terms of a visual representation. We provided stimulation for picture-word association strategies (picture and word in target language/s) by presenting a picture depicting the meaning of the words to be learned, as well as for word-word-associations (word in new language/s and its translation in the home language; see De Groot, 2011) promoting direct combination of known words and new words representing the same content. The addition of pictures simplified children's and parents' recognition of the word meaning. When looking at the filled sheets with the children in the next sessions, the monolingual children were made aware that the pictures/objects/actions presented on the sheets had other names in other languages (promoting language awareness in a plurilingual context) and were encouraged to try to pronounce these words (e.g., in Hebrew, Mandarin, etc.). The worksheets triggered multilingual learning for all children in a very concise and inclusive way. All children gained enriched early literacy experiences when looking at the different scripts. We called them "worksheets" since we added riddles, shapes to color in, drawings to be completed etc. This was done to include problem-solving and fine-motor activities (see Figure 2 for one example) to enrich the learning experience of the new words and to stimulate additional sensory input (Böttger, 2016). Moreover, we wanted to provide some activity for the moments the children would talk about the content of the session at home and implement our child-friendly, playful approach also in the context of the worksheets.

Personal relationships are important for language development (Böttger, 2016), and this includes learning languages within the family, implicit, institutionalized as well as autodidactic learning. Our attempt was, on the one hand, to strengthen the institutionalized learning, and on the other hand, to facilitate implicit and autodidactic learning by combining it with language acquisition in the family. We aimed for an 


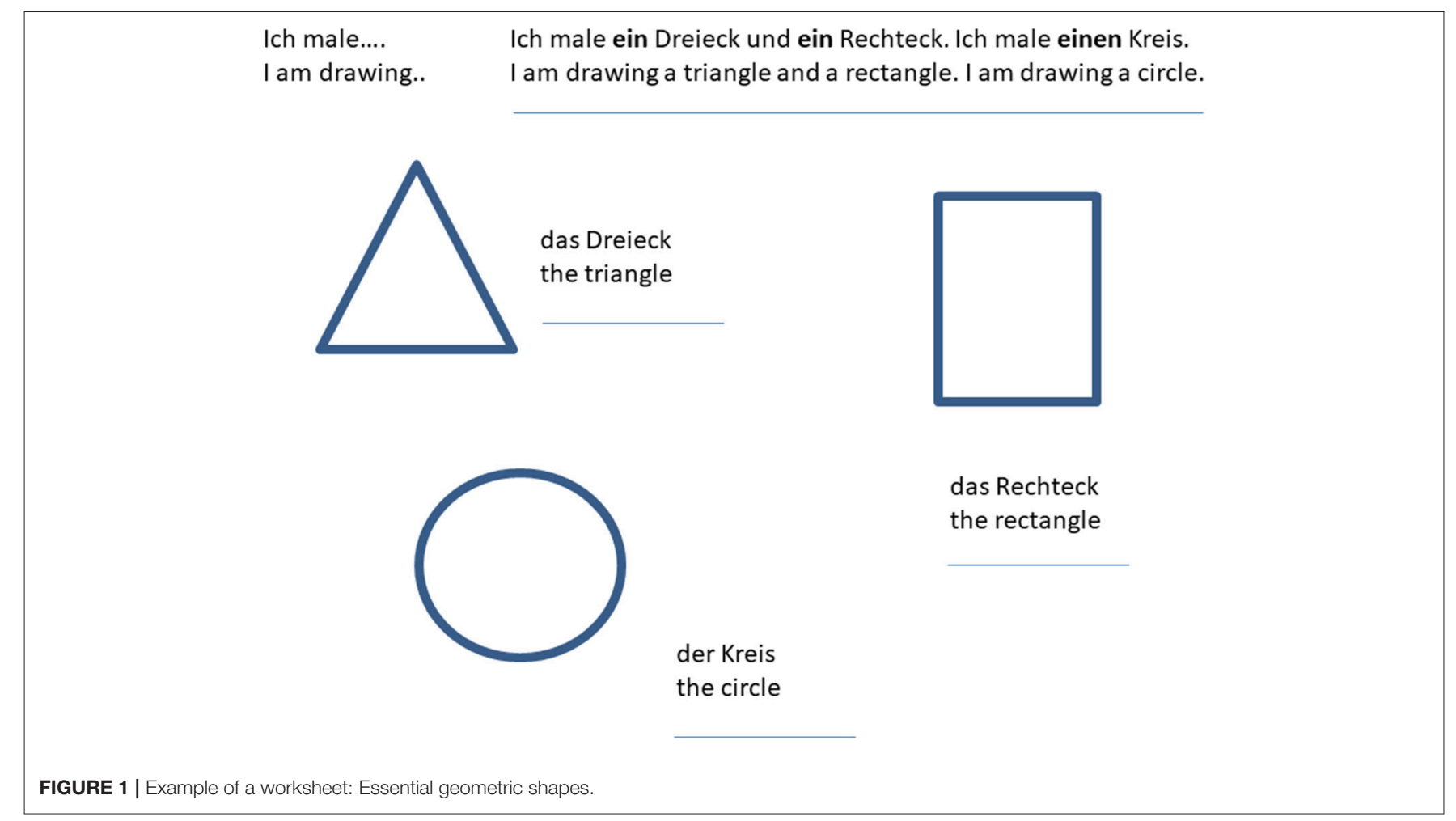

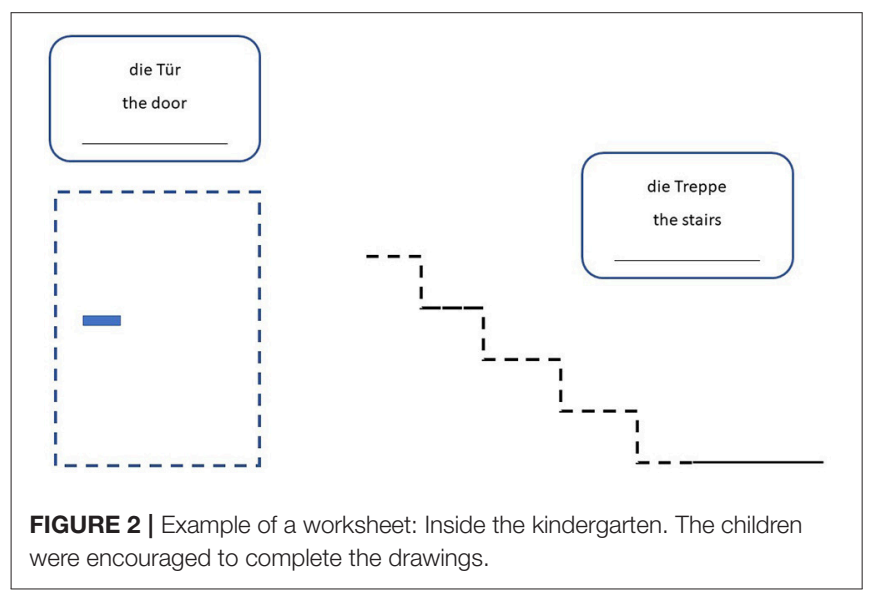

intensive collaboration with the parents to promote active support for language learning beyond the programme and the time in kindergarten. This was done by encouraging the integration of other home languages (explicitly in terms of worksheet completion in the minority home language) and by including all parents in the learning process (those who have children with minority as well as majority language backgrounds). Building on language awareness and early literacy experiences, we endorsed intercultural awareness. No language needed to be hidden, all languages were valued and included, and all children learned at least one new language. Within our programme, we fostered openness and tolerance in a plurilingual community of kindergarteners.
One might wonder how the programme dealt with the described heterogeneity of the group. The key idea was to include all children when teaching both languages, rather than to offer separate learning contexts to teach or support either German or English. By providing space for individual interaction we promoted the individual learning progress in one, two or three languages. But more than that we focused on individual active language use, as it is known that some children can remain in a receptive language use for a long time, and that it may take years to turn to active language production (Meng and Rehbein, 2007). Active language use meant for us to first provide the opportunities to use single key words and to memorize them, just as well as a training to imitate and pronounce the new words (Böttger, 2016, 136f). This was done to support children's transition from Krashen and Terrell (1983) Stage I (silent/receptive) to Stage II (early production) in every new language, and those knowledgeable of a certain language already (specifically German or English), to support development of Stage III (speech emergence) or to even enhance transition to or development of Stage IV (intermediate language proficiency). According to Langdon (2011), this model of five stages of second language development is by no means outdated. In fact, it helped us get a good idea of every child's proficiency in each language used in the intervention and guide them to the "zone of proximal development" (Vygotsky, 1978). To be able to work intensively with the children we divided them in smaller groups (10-15 children per group) and often split up the respective group into two (one language teacher per group) for word repetition games, reflections of language awareness and phonological awareness. That way we could adapt to the children's learning speed, or 
to their additional needs for explanation, interaction, repetition, etc. For short language production games we used several "language stations." At each station there was a different task offer, e.g., play a shopping game and name fruits and vegetables (plastic toys), sort and name fruits and vegetables (with pictures printed on cards) according to their color, taste small pieces of real fruits and vegetables etc. Each language teacher andwhenever possible-one of the kindergarten educators took care of one station. The purpose of this was to "train" the educators in scaffolding techniques, to provide opportunities for verbal interaction and for them to understand all of the children's developing language abilities. Moreover, we wanted to get them involved in language learning strategies and games. By familiarizing them with the vocabulary and chunks, which were the focus of each session, we hoped that they would more easily integrate them into their daily kindergarten routines with the children.

\section{The Present Study}

The programme aimed at supporting the acquisition of lexical knowledge for ALL children, independent of their knowledge prior to the intervention ("everybody learns something new"). Therefore, the study was not designed to investigate if immersion works. Our goal was not to determine whether children learn more or less in immersion compared to conventional learning settings, which would have necessitated the comparison of an immersion and a conventional learning group (for a very good example of such a study, see Bergström et al., 2016). Our interest, however, was to find out if a teaching approach can manage to address all issues relevant in current, linguistically diverse settings by including all children attending a certain kindergarten and comparing them group-wise, based on their home language use. Thus, no comparison group was included in the design.

Since solid vocabulary knowledge is crucial in the language acquisition process, we were mainly interested in empirical evidence of lexical gains in productive and receptive vocabulary. More specifically, only the most useful words were at the center of the teaching sessions. Therefore, the aim of the present study was to investigate quantitatively the learning progress in both languages (i.e., German and English) that were promoted in the invention programme PROBIMUC on a group level (monolingual German vs. international). To reach a comprehensive understanding of this learning progress, changes in lexical knowledge were determined in both languages. We used a picture naming test prior to the intervention to gain a baseline of production and comprehension abilities in both languages, i.e., the approximate lexicon size in German and English that had resulted from all prior learning experiences with the target languages. To be able to calculate the lexical gain in both skills, production and comprehension, and in both languages, we repeated the same test after the intervention. The following hypotheses were empirically tested, first comparing both groups at the level of language (hypothesis 1- German, hypothesis 2- English) and the change over time (hypothesis 3- T1 vs. T2); thereafter, we had a closer look at lexical gains per group (hypothesis 4- monolingual group, hypothesis 5 - international group). Specifically, we investigated skill-dependent (production, comprehension) development over time.

(1) (A) We predicted superior prior lexical knowledge at T1 in German for the monolingual group compared to the international group for production and comprehension due to the year-long head start of the former group in their first language. (B) We expected this difference to last (until the second testing point, T2) as we assumed that the head start would still pay off as an advantage at least for the duration of the intervention.

(2) As for lexical knowledge in English, we did not expect group differences at T1 and T2, because both groups had to learn English as a new language.

(3) Since both groups had experiences in learning their first language, we assumed that they would both reveal significant increases in lexical knowledge when tested at T2. Overall, we expected both groups to progress largely at the same rate because the programme was tailored to support language acquisition for each individual learner.

Although we expected lexical gains and retention of new vocabulary for all children, we predicted group differences.

(4) For the monolingual German group, we predicted (A) that although these children had a head start in German, acquisition of German was still ongoing and thus they would still gain lexical knowledge in that language, and more so in the production than in the comprehension skill. (B) As for gains in English, we expected the monolingual German children to increase their lexical knowledge more in English than in German being able to focus on English as their "new" language.

(5) We expected that the international group, already confronted with linguistically diverse backgrounds in their daily environment, would be able to acquire both languages in parallel and would show lexical gains in both languages. Since the kindergarten was located in Germany, it was more likely that the international group would excel in terms of lexical gains in German rather than in English (irrespective of prior language learning experiences, familiarity with German or English or both, level of proficiency in both languages). However, the international, multilingual speech environment in Germany might have made them understand that English was an important language to master. Larger gains were more likely in comprehension, since for beginning learners as well as in general, the passive lexicon (tested in the comprehension task) is usually larger than the active lexicon (tested in the production task).

Another purpose of this study was to explore parents' impressions and observations (i) of the intervention in general (hypothesis 6), (ii) of their children's interest in language learning and anticipation of the sessions (hypothesis 7), and (iii) of their children's short-term changes related to language acquisition in the time of the intervention (hypothesis 8). After the end of the intervention, we used a questionnaire 
to capture parents' observations and their impressions which were also based on child-parent communication about the sessions.

With this qualitative approach, we expected to reveal positive parental reports regarding the intervention, general anticipation of the sessions and remarkable increase in interest in language learning and fostering of a positive language learning selfconcept.

(6) For both groups we expected an equally positive impression of both the parents and the children concerning the participation in the intervention in general, since we aimed for reaching all children and parents.

(7) As we hoped to increase all children's interest in language learning with our teaching method, we expected the same interest and anticipation expressed toward their parents by both groups.

(8) We expected that parents of both groups would equally notice the changes in language learning, irrespective of the language focus their child had chosen (German or English or German and English). We predicted parental comments on changes in children's self-concept, increased active use of the languages, remarks on intercultural awareness and an impact on patterns and behavior in the family setting. We expected between-group differences only concerning the interest in the specific language(s) to be learnt (monolingual German were expected to show most interest in the English language, whereas the children with international background were expected to show interest in both German and English).

\section{METHODS AND MATERIALS}

\section{Participants}

To include the maximal possible heterogeneity, all children attending kindergarten in Potsdam were invited to participate in the free intervention programme. All parents received an information letter and gave their written informed consent for the participation of their children in the intervention. In total, 52 (mono-, bi-, and trilingual) children participated in sessions of the intervention during the time they regularly spent in the kindergarten. It should be noted that there was in general a huge fluctuation (partly due to the international academic background of some of the parents who had to move because of other jobs or back to their home country after their research stay, partly since the kindergarten was only opened 9 months before the intervention started, and many children were registered only when the intervention had already started). Therefore, data will be presented only for those children ( $n=22 ; 11$ female; mean age 3;91 years, SD: 0.53 ) who also participated in the evaluation (pre- and post-testing of lexical knowledge in both languages; for details, see below).

All participants were naïve to the purpose of the study. None of the children had any known disability. From among the 22 tested children, 11 were monolingual speakers of German (5 male). They were part of the "monolingual group". Due to a bi- or multilingual or international background, eleven children were part of the "international group". Eight participants (4 male) had an international background and spoke neither German nor English at the beginning of the intervention, but were acquiring Hebrew $(n=1)$, Japanese $(n=2)$, Mandarin $(n=1)$, Polish $(n=2)$, or Russian $(n=2)$ as their first language. Three participants (1 male) spoke German at home, but two of them had additional knowledge of one other language (Danish $n=1$, English $n=1$ ) and one had additional knowledge of two other languages (English, Hebrew).

Prior to the intervention, the parents of the children were invited to workshops (one available in German, the other one in English) on multilingualism and language acquisition. These workshops took place at the kindergarten shortly before the start of the study. We informed the parents in detail about the planned study (testing, intervention, questionnaires). After the workshops, all parents received an information letter and gave their written informed consent for their own and their children's participation. Permission for carrying out the study including the intervention was granted from the head of the kindergarten and the company responsible for the administration of the kindergarten. An ethics approval was not required as per the guideline of the ethics committee of the University of Potsdam at the time of the study, because the study was planned as a student's qualification thesis. Because the study did not involve patients, animal testing, drug-use, nor therapy, no further ethical permission was necessary according to national regulations. The study was carried out in accordance with the ethical standards laid down in the Declaration of Helsinki and the proposed guidelines for Good Scientific Practice by the DFG (German Research Foundation).

\section{Procedure}

Two weeks before (T1) and 12 weeks after (T2) the intense intervention, we administered the same word production and word comprehension test (picture naming) both in German and English (repeated measurement). Prior to the intervention, parents filled out a questionnaire on language background and language use, and after the end of the intervention a post-evaluation questionnaire on general impressions, observed changes in their children's interest in languages, etc. Both questionnaires were available in German and English.

Two skills, namely word production and word comprehension, were assessed in the lexical tests; their order of tests was randomized. For production, the tester explained to the child that the task was to name the picture shown on the card. The tester used three additional practice items for training. For the comprehension task, the tester had the target picture together with the three distractors on sheets of paper. Here the task was to point at the picture which represented the word that the tester pronounced clearly in the following way, e.g., "Please, show me the STAR!"

The children were tested individually in a quiet room in the kindergarten. The tester and the participant sat comfortably on the floor. Half of the participants started the tests in English, the other half in German. One testing session took approximately 15 min per participant. The testing session in the other language took place between 5 and 10 days later. 


\section{Materials \\ Lexical Abilities}

For both skills, production, and comprehension, we chose everyday items from semantic fields which were highly relevant for daily interaction in the kindergarten context. Semantic fields included toys and playground, clothes, food and drinks, animals, body, shapes and colors, and the kindergarten as a space.

For the word production test, we used 40 color photographs of everyday objects from among the above mentioned semantic fields. Photographs were printed on cards (each 3.13" $\times 3.35$ "). Thirty of these pictures were target words which were part of the items taught during the intervention (e.g., plate, stairs). Additionally, 10 pictures represented words which were not part of the intervention (e.g., noodle, mouth, girl) but belonged to the same semantic fields and were added to the test materials. This was done to get an indication of everyday language acquisition in the time of the intervention, as children add about 3 words per day to their active vocabulary and 14 words a day to their passive vocabulary until age 6 (Komor, 2008). The 10 filler items were intermixed in the list of target words and the order of target items was randomized.

For the word comprehension test, 30 words were chosen from the above mentioned semantic fields. For each target picture, three distractors were selected. Distractors were either (a) phonologically related, (b) semantically related, or (c) unrelated. For example, for the target "sock," the distractor for condition (a) was "soup," for (b) it was "foot," and for (c) "owl." All 3 distractor pictures (each 3.13 " $\times 3.35$ ") were printed together with the target word on a separate sheet of paper. The location of the target picture as well as the order of target items were randomized.

In each subtest, we included German-English cognates (defined as translation pairs that share both form and meaning, De Groot, 2011, p. 121). In sum, 10 cognates were part of the test materials for word comprehension, and another 10 for word production (three of which were part of the set of filler items which had not been explicitly taught in the sessions). Examples were "Finger" (engl. finger), "Glas" (Engl. glass).

\section{Background and Language Use Questionnaire}

A German-English questionnaire was prepared for the parents to fill out prior to intervention. They were asked to report which language/s they (i.e., mother/father/siblings) used with the child and which language/s the child used with them (mother/father/siblings). We were further interested in the language/s the child used in his/her daily routine and the language/s each of the parents used in their daily routine.

\section{Parents' Evaluation of the Intervention}

After the end of the programme, we asked the parents to provide written evaluations of specific aspects of the intervention (either in English or German). In our German-English questionnaire, we used an open-ended format and focused on four topics: their general impressions (including materials such as posters, folders, etc.); the child perspective and stories told by their child after sessions; comments on their child's interest in and anticipation of the sessions; and parental observations regarding the child's language development in the time of the intervention.

\section{Participation in Sessions}

In order to determine whether frequency of attendance had an impact on vocabulary gain, we needed a clear indication of how often every single child participated in the sessions of the intervention. For that purpose, we recorded the frequency of attendance on a name list.

\section{Data Preprocessing and Analysis Lexical Abilities}

In terms of a quantitative assessment of children's lexical knowledge and vocabulary gain, we coded the children's verbal responses as correct/incorrect and calculated sum scores for lexical knowledge at T1 (= two weeks before) and at T2 (= 12 weeks after intense intervention) for each language (German, English) and each skill (production, comprehension), respectively.

We analyzed the tasks in each language separately by using IBM SPSS Statistics 24. Due to the small sample size, we were only able to run $t$-tests for each task to compare language and group (monolingual vs. international) performance. We calculated lexical gain as the difference between T1 and T2 in the sum score of correct responses per task and language for the analysis of our repeated measures data.

\section{Background and Language Use Questionnaire}

The answers obtained from the parents in the first GermanEnglish questionnaire were coded and prepared for analysis.

\section{Parents' Evaluation of the Intervention}

Written parental responses were first digitized. We then extracted and classified key concepts in the parental responses to our openended questions: own impressions including child perspective, child interest, and change in language development. We then counted the frequency of appearance of each key concept for each question per group. Finally, we summarized the responses for each key concept per question.

\section{Participation in Sessions}

After the intervention, a sum score was calculated indicating the frequency of attendance per child.

\section{RESULTS}

We first present the results of the quantitative analysis of the tests investigating lexical knowledge in German and English prior and post-intervention (section Quantitative Approach: Lexical Abilities). The results will be presented for betweengroup comparisons (lexical knowledge per language at T1 and at T2, section Between-Group Comparison of Basic Lexical Knowledge Per Skill at T1 and at T2) as well as for withingroup comparisons to determine if the groups gained lexical knowledge from T1 to T2 (section Within-Group Comparison of Increased Lexical Knowledge Per Skill And Language at T2). Finally, the results of more detailed analyses specify the extent of lexical gain per skill and/or language to reveal which group succeeded most [section Between-group comparison of lexical gain per language and skill (mono vs. international)]. 
TABLE 1 | Means and standard deviations in parentheses for lexical knowledge of groups per skill for German.

\begin{tabular}{|c|c|c|c|}
\hline & Monolingual & International & $\begin{array}{l}\text { p-value } \\
\text { (between- } \\
\text { group) }\end{array}$ \\
\hline \multicolumn{4}{|c|}{ LEXICAL KNOWLEDGE-GERMAN SUM } \\
\hline Production SUM & $71.27(3.95)$ & $35.91(28.98)$ & $0.001^{\star \star \star}$ \\
\hline Comprehension SUM & $58.09(2.73)$ & $43.09(15.55)$ & $0.005^{\star \star}$ \\
\hline \multicolumn{4}{|c|}{ LEXICAL KNOWLEDGE-GERMAN PRODUCTION } \\
\hline G Produc. T1 SUM & $34.18(2.56)$ & $14.55(15.10)$ & $<0.001^{\star \star \star}$ \\
\hline G Produc. T2 SUM & $37.09(1.81)$ & $21.36(14.56)$ & $0.002^{\star \star}$ \\
\hline$p$-value (T1 vs. T2) & $<0.001^{\star \star \star}$ & $0.005^{\star \star}$ & \\
\hline \multicolumn{4}{|c|}{ LEXICAL KNOWLEDGE-GERMAN COMPREHENSION } \\
\hline G Compr. T1 SUM & $28.55(2.12)$ & $18.82(10.53)$ & $0.007^{\star *}$ \\
\hline G Compr. T2 SUM & $29.55(0.69)$ & $24.27(5.29)$ & $0.004^{\star \star}$ \\
\hline$p$-value (T1 vs. T2) & $0.058+$ & $0.013^{\star}$ & \\
\hline
\end{tabular}

The $p$-value in the column at the right refers to the comparison between groups (monolingual vs. international), while the p-value below the SUM means and SD refers to the within-group comparison between T1 (test before the intervention) and T2 (test after the intervention). The asterisk indicates significant effects below an alpha-level of 0.05. ${ }^{* \star *} p<0.001,{ }^{* *} p<0.01,{ }^{*} p<0.05,{ }^{+} p<0.1$

Following this, we describe the results of our qualitative analysis of the questionnaire data focusing on background and language use (section Qualitative Approach: Background and Language Use Questionnaire). In section Parents' Evaluation of the Intervention, we present the results of the evaluation from the parents' point of view.

To compare lexical gains for children with monolingual background and children with international background, children were grouped based on the language use data collected by means of the parental questionnaire (see section Background and Language Use Questionnaire and Qualitative Approach: Background and Language Use Questionnaire. for more detail). Eleven children ( 5 male) were raised in a monolingual family and constituted the "monolingual group," the "international group" ( $n=11 ; 5$ male) was composed of children who used more than one language or were from an international background (e.g., parents were from Japan and for a research stay in Germany; parents are German but lived for several years, e.g., in Denmark). The two groups did not differ significantly in age (mean age 3.91 in each group), gender (5 boys per group), or frequency of attendance in sessions (mean frequency 14.91 per group, SD mono 3.81, SD multi 3.62). The frequency of attendance in the sessions varied in both groups between 6 and 18 sessions.

\section{Quantitative Approach: Lexical Abilities}

Bivariate correlations revealed that there was no correlation of lexical knowledge at T1 and T2 per language and skill with age, gender or number of participation in sessions, but there were significant correlations of lexical knowledge with group. We found higher scores for German for the monolingual compared to the international group (for more details, see below and see Table 1), more specifically in German production (at T1: Pearson's $r=-0.689$ and at T2: $r=-0.622$ ), and in German comprehension (at T1: $r=-0.557$ and at T2: $r=-0.591)$.
TABLE 2 | Means and standard deviations in parentheses for lexical knowledge of groups per skill for English.

\begin{tabular}{|c|c|c|c|}
\hline & Monolingual & International & $\begin{array}{c}p \text {-value } \\
\text { (between- } \\
\text { group) }\end{array}$ \\
\hline \multicolumn{4}{|c|}{ LEXICAL KNOWLEDGE -ENGLISH SUM } \\
\hline Produc. SUM & $5.55(5.29)$ & $10.18(12.12)$ & 0.259 \\
\hline Compr. SUM & $32.27(9.43)$ & $33.27(13.79)$ & 0.873 \\
\hline \multicolumn{4}{|c|}{ LEXICAL KNOWLEDGE－ENGLISH PRODUCTION } \\
\hline E Produc. T1 SUM & $0.55(1.21)$ & $1.64(2.06)$ & 0.146 \\
\hline E Produc. T2 SUM & $5.00(4.79)$ & $8.55(10.13)$ & 0.307 \\
\hline$p$-value (T1 vs. T2) & $0.009^{\star \star}$ & $0.019^{*}$ & \\
\hline \multicolumn{4}{|c|}{ LEXICAL KNOWLEDGE - ENGLISH COMPREHENSION } \\
\hline E Compr. T1 SUM & $14.09(5.26)$ & $13.64(7.51)$ & 0.871 \\
\hline E Compr. T2 SUM & $18.36(4.84)$ & $19.64(6.76)$ & 0.617 \\
\hline$p$-value (T1 vs. T2) & $0.003^{\star \star}$ & $<0.001^{\star \star \star}$ & \\
\hline
\end{tabular}

The $p$-value in the column at the right refers to the comparison between groups (monolingual vs. international), while the p-value below the SUM means and SD refers to the within-group comparison between T1 (test before the intervention) and T2 (test after the intervention). The asterisk indicates significant effects below an alpha-level of 0.05. ${ }^{* \star *} p<0.001,{ }^{* *} p<0.01,{ }^{*} p<0.05$.

\section{Between-Group Comparison of Basic Lexical Knowledge Per Skill at T1 and at T2}

First, we determined the lexical knowledge in German and English for both groups before the intervention (i.e., at T1), as a baseline. Table 1 presents a summary of the data and statistical effects for performance per group (monolingual vs. international) for each of the tasks (production and comprehension) in German at the two testing points (T1 and T2). Regarding the German lexical abilities, we found group differences before the intervention, as expected (hypothesis 1A). The monolingual group had significantly higher sum scores in German than the international group at $\mathrm{T} 1$ for both production $\left[t_{(20)}=4.252\right.$, $p<0.001]$ and comprehension $\left[t_{(20)}=3.003, p=0.007\right]$. The continuous significant lexical superiority of the monolingual group was evident in $\mathrm{T} 2$ for both production $\left[t_{(20)}=3.555\right.$, $p=0.002]$ and comprehension $\left[t_{(20)}=3.276, p=0.004\right]$ (supporting hypothesis 1B).

Table 2 shows a summary of the data and statistical effects for performance per group (monolingual vs. international) in English for each of the tasks (production and comprehension) at T1 and T2. Other than for German, we did not find any between-group differences for English (as predicted in hypothesis 2 ), as both groups were hardly able to name the presented pictures in English at T1 $\left[t_{(20)}=-1.512\right.$, n.s.]; they both had higher sum scores on the easier task, namely the comprehension task at $\mathrm{T} 1\left[t_{(20)}=-1.049\right.$, n.s. $]$. Compared to the monolingual group, the international group had higher scores in production $\left[t_{(20)}=0.164\right.$, n.s. $]$ and comprehension $\left[t_{(20)}=-0.508\right.$, n.s. $]$ at T2. However, the numerical differences did not reach significance (as predicted in hypothesis 2).

\section{Within-Group Comparison of Increased Lexical Knowledge Per Skill and Language at T2}

Overall, we found a significant increase in lexical knowledge for each group [see Table 1, $p$-value (T1 vs. T2) for production 
and comprehension in German, and Table 2 -value (T1 vs. T2) for production and comprehension in English]. This finding confirmed our prediction (hypothesis 3 ) that both groups were sufficiently supported in the intervention to learn both languages in parallel, largely at the same rate.

Paired $t$-tests which compared within-group lexical gains from $\mathrm{T} 1$ to $\mathrm{T} 2$ revealed significant increases for the monolingual group for German production $\left[t_{(10)}=-4.770, p=0.001\right]$ but only a marginal significance for the monolingual group regarding comprehension in German $\left[t_{(10)}=-2.141, p=0.058\right.$ ] (as predicted in hypothesis $4 \mathrm{~A}$ ). We found support for hypothesis $4 \mathrm{~B}$ as both lexical gains in English were significant: for English comprehension $\left[t_{(10)}=-3.869, p=0.003\right]$ and for English production $\left[t_{(10)}=-3.234, p=0.009\right]$. For the international group, paired $t$-tests yielded significant increases from $\mathrm{T} 1$ to $\mathrm{T} 2$ for German production $\left[t_{(10)}=-3.551, p=0.005\right]$, for German comprehension $\left[t_{(10)}=-3.012, p=0.013\right.$ ], for English production $\left[t_{(10)}=-2.802, p=0.019\right]$, and for English comprehension $\left[t_{(10)}=-5.357, p<0.001\right]$, supporting hypothesis 5 .

\section{Background and Language use Questionnaire}

In Table 3 lexical gain is presented for each group, skill and language. In both languages and skills, higher values were found for the international group, indicating larger lexical gains. Independent sample $t$-tests comparing the extent of lexical gain between the groups revealed a marginal significance for German production $\left[t_{(20)}=-1.940, p=0.067\right]$ and a significance for German comprehension $\left[t_{(20)}=-2.382, p=0.027\right.$ ] for that group (supporting hypothesis 5 ). The gain in lexical knowledge in English was not significant between the groups [production: $t_{(20)}=-1.098$, n.s.; comprehension: $t_{(20)}=-0.869$, n.s.], confirming additionally hypothesis 3 .

Bivariate correlations yielded no significant correlation of lexical gain per group, language and skill with age, gender or number of participation in sessions.

TABLE 3 | Means and standard deviations in parentheses for lexical gain per group, language and skill.

$\begin{array}{cc}\text { Monolingual International } & p \text {-value } \\ \text { (between } & \text { group) }\end{array}$

group)

\begin{tabular}{lccc}
\hline GAIN GERMAN & & & \\
Production & $2.91(2.02)$ & $6.82(6.37)$ & $0.067+$ \\
Comprehension & $1.00(1.55)$ & $5.45(6.01)$ & $0.027^{\star}$ \\
$p$-value (between skills) & $<0.001^{\star \star *}$ & 0.569 & \\
GAIN ENGLISH & & & \\
Production & $4.45(4.57)$ & $6.91(8.18)$ & 0.285 \\
Comprehension & $4.27(3.66)$ & $6.00(3.71)$ & 0.395 \\
$p$-value (between skills) & 0.892 & 0.739 & \\
\hline
\end{tabular}

The $p$-value in the column at the right refers to the comparison between groups (monolingual vs. international), while the p-value below the SUM means and SD refers to the within-group comparison between skills (production vs. comprehension). ${ }^{* * *} p<$ $0.001,{ }^{\star *} p<0.01,{ }^{*} p<0.05,{ }^{+} p<0.1$.

\section{Qualitative Approach: Questionnaires and Evaluation \\ Background and Language use Questionnaire}

Results from the analysis of the German-English questionnaire data showed that in the monolingual group, all children used only German as language of communication with their parents and siblings. Children from the international group, however, used either their first language for communication with their parents and siblings (one used Hebrew, two Japanese, one Mandarin, two Polish, and one Russian), or their two first languages (GermanEnglish, but only with the mother) or even their three first languages (German-English-Hebrew, Russian-English-German). Interestingly, parents' information about their own language use with their child was not once different from the information about the child's language use with family members.

In their daily routines, children in the monolingual group were all using only German. In the international group, responses included several different language use combinations: German-English, German-Polish, German-Danish, GermanEnglish-Polish, German-English-Hebrew. The other children in this group used only their first language (Hebrew, Japanese, Russian, Polish, Mandarin) at the time of data collection.

We gathered the following information about the language/s each of the parents used in their daily routine: Six parents belonging to the monolingual group reported that they used only German. Three mothers answered that they also used English at work (1 mother) or for communication with friends (2), and two fathers mentioned the use of English at work. In all reported cases, maximally only one parent per family indicated that they used one additional language in the context of work or friendship.

The information gathered from the international group revealed a very different, plurilingual picture. In the work context, three mothers reported that they used German-English, and one Polish-English. The other mothers did not provide any response for the work context. For communication with friends, two mothers mentioned that they used German and English, one English-Danish-German, one Hebrew-French-German-English, one German-English-Polish, and one Mandarin-English. Fathers responded that they used English or German and English at work. For communication with friends, they reported that they used Hebrew, German-Polish, German-English, GermanEnglish-Polish, Mandarin, Japanese, Russian or Polish.

\section{Parents' Evaluation of the Intervention}

In the responses to the first question focusing on parental impressions of the participation in the intervention, a number of different key concepts were mentioned. Since most of them were complemented by comments from a child perspective, we combined the responses to question 1 and 2 as follows: (A) Three monolingual and four international parents remarked that they noticed that the children were "having fun" participating in the intervention. (B) Four monolingual and three international parents noted that it was a "very nice project" and that they were very happy with the project overall. Moreover, they noticed that it was "well organized, the best one can achieve with children." (C) Regarding the posters, two monolingual parents stated that 
"the posters showed that the kids had fun," and that "parents could get an idea of what happened in the intervention." (D) The folders in which the children collected their worksheets were mentioned as well. Parents' comments (5 monolingual, 6 international) focused on the effect of the folder, how "proudly" the children showed it to their parents, how much they liked to look at it at home, to color in, to show what they had learned that day, how much they urged their parents to look at it and how "angry they would get if the parents hadn't looked at it with them the day before the next session." Three monolingual and one international parents stated that the "pages with names of things were very helpful" for them and the children to remember and repeat the new words, and for the parents to see the topics of the sessions. They concluded that "the pages provided a great summary" of the project. (E) Moreover, one monolingual and two international parents remarked on the effect of the intervention. They stated that it "promoted the feeling of community among the children," that it was "playful learning," that it "helped them learn new words, helped them gain confidence to speak and to use the new languages." Some children always sang the song, which was part of the intervention, at home. (F) Others loved the cuddly toys, and parents reported that the children remembered everything the cuddly toys did. (G) As for general development, two monolingual parents stated that they as parents were "very enthusiastic about the child's development," that the child "always loved to participate," and that "they were very sad about the fact that the intervention had ended." As hypothesized (hypothesis 8 ), parents in both groups expressed positive statements about the intervention.

For the second question, we gathered information about the children's anticipation of and interest in the intervention. Nine monolingual and seven international parents included remarks about their children's "great enthusiasm for the programme" and called it a "highlight" in their children's kindergarten life. They described how "keen the children" were on the programme, how much they liked to go to the sessions, and how happy they always were after the sessions. One parent even reported that his child had such strong anticipation that sometimes he couldn't wait for it to start. Overall, both groups shared their own observations regarding anticipation of interest in the programme, which were evident in their children's behavior. Both groups agreed on the same degree of interest and anticipation, as predicted in hypothesis 7.

Finally, the third question aimed at changes in children's languages and learning. One monolingual parent noticed that her child "realized that there were other languages." Two monolingual and two international parents observed how much the intervention raised their children's interest in the English language. One mother reported how much her child liked it that the mother used more English at home. Moreover, one international family described how the intervention and language learning "had infiltrated our home as more German and English words were incorporated into conversations." Four monolingual parents noticed how "proud" their children were being able to use some words in English and how proudly they would talk about the newly learned words. Two monolingual and two international parents reported that their children asked them regularly to study the folder with them. In some families this turned into "study the folder instead of a good night story." One international parent reported that his son "seemed to recognize more than $70 \%$ of the names in the folder." Additionally, six monolingual parents described the children's "joy of learning" and how much their children "liked to repeat words at home," "name colors in English," "sing songs in English"; others "often named things in English," and included English words and sentences in their family conversations. Five monolingual and three international parents reported that their children often asked for translations in English. Another child pronounced German words in English or sometimes responded in English to a question asked in German. Two international parents noticed how their children's German language skills improved, three other international parents reported on improvements of both German and English skills. One international parent explained that her daughter "took a long time to adapt to new languages," but recently, she "had heard her speaking out with both German and English words." Confirming hypothesis 8, parents from both groups included comments about changes in language learning and use, their children's self-concept, and intercultural awareness in their responses to our open-ended questions. In particular, between-group differences were apparent in family's language use, since monolingual families used more English at home whereas international families often included both new languages in their family conversations. Monolingual children revealed a particular interest for the English language, while international children expressed interest and active use of both new languages, German and English.

\section{DISCUSSION}

The present study investigated the effects of a programme uniquely designed for highly-heterogeneous learners at the kindergarten level on their acquisition of languages. We observed lexical learning of two groups in a kindergarten in Germany which were submersed in two languages (German and English). One group was composed of children with a monolingual German background striving to learn English while the other group grew up in an international environment and was confronted with two new languages in the kindergarten context. We wanted to determine whether the language teaching approach which we constructed for this highly-heterogenous group of children would work in the sense that each child's language learning progressed. Beyond that, we were interested in the effects of the intervention on the children and the parents and included a questionnaire for that purpose.

\section{Learning Progress Per Group and Language}

In this study, we used two measures for lexical assessment. While we used the receptive part to evaluate passive lexical knowledge and gains, we tested active knowledge and availability to produce the words in the target language with the productive part. The results of the quantitative analysis revealed that all children progressed in their knowledge of German and English 
in the time of the intervention (hypothesis 3). A head start in German was evident for the monolingual group in terms of a larger vocabulary before the intervention. This advantage lasted at least until the second test time points and was most likely due to the monolingual language environment in which they had been exposed to that language only. This confirmed our first hypothesis.

With regard to the international group, we observed significant progress for both new languages, which confirmed hypothesis 5. The contrasts in skills in German and English were not significant indicating that the gain was similarly distributed among both production and perception. Their multilingual background might explain this finding. Children in this group were raised in a plurilingual environment, as their multilingual parents reported that they used a number of languages for family, friend, and work communication. Not only was multilingualism apparently the norm for this group of children, but it is likely that they had realized that they needed knowledge of German and English to get along well in their kindergarten life. This group of children demonstrated remarkable progress as they excelled in lexical gains in German.

Interestingly, paired $t$-tests comparing the skills per language and group revealed that the monolingual German group gained significantly more lexical knowledge in production of German than in comprehension, $t_{(10)}=5.186, p<0.001$. This provides support for hypothesis $4 \mathrm{~A}$, namely that the monolingual children improved their productive skills in particular, which represented the more difficult skill in the ongoing acquisition of German. The finding might, on the one hand, be explained by ceiling-effects for most of the children in this group in the German comprehension test, as they only showed significant improvement for German language production. By and large, the results in this study are well in line with the inherent difference between receptive and productive recall. When asked to produce a certain word depicted on a stimulus picture, a successful execution of this task demand is based on having full knowledge of the form of the word and being able to pronounce it. In contrast, for comprehension tests, the requirements are less specific, meaning that it is sufficient to perform based on memory traces, which are less consolidated or less complete (Griffin and Harley, 1996). Hence, it was easier to perform well on the comprehension than on the production test.

On the other hand, the monolingual children's focus was probably on acquiring the new language, which they were confronted with in kindergarten due to the English caretaker; however, this new language apparently was made more accessible to them in the course of the intervention. And in fact, the monolingual group progressed more in English than in German, supporting hypothesis 4B. According to the parental reports, their children became more highly motivated to learn the language they could easily avoid before by using German as the sole language for interaction with kindergarten educators. In fact, they finally might have been able to make use of the fact that they had already learned a first language. Due to the methodological approach of the intervention, they might have consolidated their knowledge of German and built up their knowledge in English.
In English, both groups did not differ regarding their productive and receptive skills prior to the intervention, supporting hypothesis 2 . This result strengthens the point that even when the English caretaker tried to communicate with the children, he could not succeed, because they simply had not yet learned English. The English testing results at T2 showed that they learned apparently at the same rate since lexical gains were equally large for both groups (hypothesis 3 ).

The study revealed that for minority children it would be possible to acquire two new languages in parallel if a methodological approach such as the one described here was used. Although some of the elements integrated in the approach were formal (the worksheets, repetition of learned words, etc.), we aimed for creating a learning environment as natural as possible, including sustained interaction with each child, using play, games, theater, etc. Therefore, we suggest that both opportunities for implicit and explicit learning should be included in teaching programmes for early year settings, in particular when they are linguistically diverse. With respect to language mixing, the children were not confused by the teachers' flexible language use and could rely on language use associations with the cuddly toys, if necessary. The children revealed an impressive mastery of language control in the testing situations. Cross-language interference was hardly observed.

The finding that the international group improved in both languages equally well per skill was noticeable. This showed that this group of children profited from the intervention even with respect to acquisition of both new languages. This finding revealed that these children learned at the same rate as the monolingual children, which confirms hypothesis 3. In line with the current debate about the cognitive advantage (e.g., Kaushanskaya and Marian, 2009), one might argue that the international children were able to make use of enhanced learning abilities in such a way that they would reveal equally large lexical gains in English and larger lexical gains in German compared to their monolingual peers.

\section{The Use of Fast Mapping in Word Learning}

Learning new words is a complex process, and a crucially important one for children. Word learning for children, especially for those with other home languages than the one used in kindergarten or school, needs specific support (Apeltauer, 2004). In early childhood, the name of a concrete object (such as a tree) needs to be combined with the meaning (of "tree"), the concept (of "tree"), and the acoustic representation and pronunciation of the word ("tree"). From the age of 2 years onwards, toddlers are usually fast word learners which is explained by the mechanism of "fast mapping" (Carey and Bartlett, 1978). Fast mapping denotes the ability to quickly combine mentally a word with an object, even if it is heard only once. "Extended mapping" (Carey, 1978) is the consecutive continuous completion of information during every new confrontation with the word.

In a kindergarten study by Karas (2016) three different conditions of fast-mapping contexts were compared in a group of 75 children (between 5 and 9 years of age; $n=24$ monolingual, 
$n=51$ with a home language different from German). A new word ("zilp") was introduced in three different contexts: embedded in a story, in a story with a picture, or named explicitly? As there was only one single target item, conclusions needed to be carefully drawn from the results. They indicated that for multilingual children, explicit naming was the most successful acquisition context for receptive skills, while for production, it was the story context. The insight we gained from this study was nonetheless that in order to support the acquisition of vocabulary in preschool children, different learning contexts should be used for optimal support of both productive and receptive skills (Karas, 2016). For our monolingual group, it seems that they were still able to improve language production in German, probably relying on fast mapping and semantic refinement of their mental representations. For the international group, word learning most likely did not work in the same way. Tracy (2008) claimed that due to bilingual language awareness, bilinguals were used to the fact that objects had different names. Strictly speaking, our international children were not yet bilinguals. They were speakers of a home language and were new in Germany and to the kindergarten. We can only speculate that these children were already sufficiently immersed in their international and plurilingual environment that they may have internalized the concept that one object has several names.

\section{Home Language Inclusion Involved Parents}

To our knowledge, there are currently several attempts to implement a languages-curriculum for schools, by integrating the teaching of all additional foreign languages, sometimes by including the language of the school as well (e.g. L1 French, L2 German and L3 English in parts of Switzerland in the project EOLE goes English, Elmiger, 2008). Other approaches involve language-focused activities for multilingual learners across the curriculum to promote cross-curricular learning and assessment (Conteh, 2015, chapters 4-6). However, the use of home languages and cultures is exempt from these activities (see Conteh, 2015, chapter 7) since the strategies for using home languages and cultures is considered and described only as a way to promote pupils' independent learning. Conteh (2015, p. 65) stressed that "we must value the knowledge that our pupils bring to the classroom and help them find spaces in which they can construct their own ways of learning, beginning from what they already know". Still, the home languages are not yet included in the day-by-day language activities in school. They are still limited in terms of inclusion in the schools, being rather included as a "special case" for certain activities, e.g. a name tree (Conteh, 2015, pp. 168-169), greetings in different languages (p. 167), reading of multilingual books (p. 167), preparation of trilingual books (pp. 64-65). Similar approaches can be found in the compilation of reports supported by the European Center for Modern Languages. Several schools participated in the whole-languages curriculum which was established by the project PLURCUR (Allgäuer-Hackl et al., 2015). Only very few schools faced the challenge of integrating home languages and cultures in the school (e.g., Collège La Binquenais in Rennes, France) or for certain school activities at a high school in Bozen, Italy (e.g., reading books in the language of their choice such as Urdu, Hindi, English, Ladin). Fasse (2015) described a project at a high school in Cologne, Germany, which used plurilingual acting. In the frame of this afternoon school activity, students participating in the theater group were encouraged to use "all their languages" (e.g., home languages, dialects, sociolects, etc.).

In a way, some of the elements constituting the concept of ProBiMuc may remind us of the school-concept of "specially designed academic instruction in English" (SDAIE) (Peregoy and Boyle, 2008). SDAIE is characterized by a focus on engaging the children's interest, in teaching vocabulary, idioms, and the use of visuals to increase the comprehension of ideas and concepts, in slow speech rate and clear articulation, in teacher models, in including gestures and facial expressions when needing to make a point, in the teaching of writing and listening (Langdon, 2011). However, one has to recall that ProBiMuc is a programme for kindergarten children and is not aiming at promoting the academic instruction for school-aged children and the teaching of content subjects in English at school. ProBiMuc rather centers on promoting the learning of one, two or three languages in pre-school settings.

In that sense, this programme is unique. It pushed the children a few steps further toward the functional use of two languages which were crucial in their kindergarten life, and even toward their school-readiness. Most importantly, the inclusion of the parents and the home languages seems to have played an outstanding role for the parents' appreciation of the intervention and the success of all participants (confirming hypothesis 6). The fact that parents reported having observed changes in their children's attitude toward language learning in the course of the intervention implied that an intervention was urgently neededfor the children, for the parents as well as for the kindergarten educators. The programme helped them to get out of a rather frustrating situation of submersion and to develop toward an immersion setting.

The deliberate inclusion of the home languages, with their prominent place on the work sheets was apparently a highly successful measure to value the home languages and to effectively initiate more involvement of the parents. The focused and specific input with selected semantic fields of high relevance for all kindergarten communication made it possible for children to include these new words into their daily communication, even at home (providing support for hypothesis 8). The parents were able to catch up with their children's learning and opened up to new words even during family conversations, as was described in the parental reports. The new language(s) "infiltrated" family interactions. Language learning was a topic at home as the monolingual as well as international children urged their parents to look at and work with the folder (sometimes even instead of bedtime stories (providing support for hypothesis 7). It seemed like the children had grasped the importance of language learning, the personal relevance for them in the kindergarten context and the impact it had on their self-esteem. The many silent and shy children were no longer left alone to struggle with language acquisition, but rather were provided with tools, support and comprehensible segments. 


\section{Limitations of the Study}

Only about half of the children participated in both language tests at each test times. This unfortunately caused a reduction of data available for analysis. The other half of the children either did not yet attend the kindergarten when the intervention started, or they had left the kindergarten before the end of the intervention, or they had been ill for a longer period of time or on vacation. Thus, one would not argue that the children who participated were only the highly-motivated children; a selection bias can be excluded. Due to the small number of children, we could not compare the multilingual children according to their background (born in Germany with migration experience in their families vs. born abroad with own migration experience). Therefore the "international group" was comprised of children from these two groups and no further distinction was made between them.

Moreover, one might wonder why we did not include SES or other control variables (cognitive abilities such as reasoning, verbal short-term memory; proficiency in the children's home language). Which specific factors influence learning rate and learner success is a question that is different from the more general one we asked here. We wanted to determine if we could reach all children and motivate them to enlarge their linguistic capital irrespective of the many factors that differentiate them and that might influence learning rate and learner success. Importantly, it should be noted that the two groups did not differ significantly in age (mean age 3.91 in each group), gender ( 5 boys per group), or frequency of attendance in sessions. Moreover, the parents from both groups were similar in terms of SES as they resided in the area of the town where one large university campus and several research institutes were located. Most of these parents studied or were working at the university or research institutes.

A qualitative analysis of children's lexical knowledge and vocabulary gain was beyond the scope of this paper. This would have included the analysis of the verbal responses with regard to the error domain. For production, the verbal responses could be categorized as semantic, phonological, or unrelated error in the target language or as cross-language interference. For comprehension, the distractor categories could

\section{REFERENCES}

Allgäuer-Hackl, E., Brogan, K., Henning, U., Hufeisen, B., and Schlabach, J. (eds.). (2015). MehrSprachen? PlurCur! Berichte aus Forschung und Praxis zu Gesamtsprachencurricula. Baltmannsweiler: Schneider Verlag Hohengehren.

Apeltauer, E. (2004). "Sprachliche Frühförderung von Zweisprachig Aufwachsenden Türkischen Kindern im Vorschulbereich," in Bericht über die Kieler Modellgrupe (Flensburg: Universität).

Barik, H., and Swain, M. (1975). Three-year evaluation of a large-scale early grade French immersion program: the ottawa study. Lang. Learn. 25, 1-30.

Bergström, K., Klatte, M., Steinbrink, C., and Lachmann, T. (2016). First and second language acquisition in German children attending a kindergarten immersion program: a combined longitudinal and cross-sectional study. Lang. Learn. 66, 386-418. doi: 10.1111/lang.12162

Böttger, H. (2016). Neurodidaktik des Frühen Sprachenlernerns. Wo die Sprache Zuhause ist. Bad Heilbrunn: Klinkhardt/UTB.

Carey, S. (1978). “The child as word learner," in Linguistic Theory and Psychological Reality, eds M. Halle, J., Bresnan, and G.A. Miller (Cambridge: MIT Press), 264-293. be used as follows: semantic, phonological, or unrelated. Due to the rather small sample, an interpretation of the change of frequency in error domain production could only have been speculative.

\section{CONCLUSION}

One may want to rethink how important professionalization is. Knowledge about language acquisition, particularly in the context of migration and multilingualism, needs to be complemented by concrete strategies and understanding how language acquisition can be supported effectively in linguistically diverse contexts. More than ever, it seems necessary to maintain a flexible, adaptive spirit when communicating with young children. Understanding the linguistic situation in which they live is a first step toward taking their linguistic needs into account. Diversity management and intercultural pedagogics are approaches which could be helpful for kindergarten contexts these days.

\section{AUTHOR CONTRIBUTIONS}

JF conceptualized, planned, and realized the intervention; she designed the project including testing and parents' questionnaires. She was not involved in data collection (vocabulary testing prior and post the intervention). She preprocessed, analyzed, and interpreted the data. She drafted the manuscript.

\section{ACKNOWLEDGMENTS}

We thank the children and the parents who participated in this study. Further we are grateful to Tanja Rinker and Anna Schneider for their help with the data collection (lexical tests). We thank in particular Henriette Stoll for her help in planning sessions and supporting me in the intervention. We are very grateful to the two reviewers and Dr. John W. Schwieter for very helpful comments.
Carey, S., and Bartlett, E. (1978). Acquiring a Single New Word. Papers and Reports on Child Language Development, 15, 17-29.

Conteh, J. (2015). The EAL Teaching Book. Promoting Success for Multilingual Learners, 2nd Edn, London: Sage Learning Matters.

Council of Europe (2001). Common European Framework of Reference for Languages: Learning, Teaching, Assessment. Cambridge: Cambridge University Press.

Cummins, J. (2009). Multilingualism in the English-language classroom: pedagogical considerations. TESOL Q. 43, 317-321. doi: 10.1002/j.1545-7249.2009.tb00171.x

De Groot, A. M. B. (2011). Language and Cognition in Bilinguals and Monolinguals. An Introduction. New York, NY: Psychology Press.

Dewaele, J. M. (2010). Emotions in Multiple Languages. London: Palgrave.

Dörnyei, Z. (2005). Psychology of the Language Learner: Individual Differences in Second Language Acquisition. Mahwah, NJ: Lawrence Erlbaum Associates.

Elmiger, D. (2008). "L'introduction de l'anglais comme L3 à l'école primaire romande," in Mehrsprachigkeit: Lernen und Lehren, Multilingualism: Learning and Instruction, Le Plurilinguisme: Apprendre et Enseigner, O Plurilinguismo: 
Aprender e Ensinar, eds M. Gibson, B. Hufeisen, and C. Personne (Baltmannsweiler: Schneider Verlag Hohengehren), 175-186.

Fasse, G. (2015). "Ein vielsprachiges Theaterprojekt in der Schule: Im Meer der Sprachen," in MehrSprachen? -PlurCur! Berichte aus Forschung und Praxis $z u$ Gesamtsprachencurricula, eds Allgäuer-Hackl, E., Brogan, K., Henning, U., Hufeisen, B., and Schlabach, J (Baltmannsweiler: Schneider Verlag Hohengehren), 125-136.

Festman, J., Poarch, G., and Dewaele, J. M. (2017). Raising Multilingual Children. Bristol: Multilingual Matters.

Festman, J., and Rinker, T. (2014). ProBiMuc (a Programme for Bilingual and Multilingual Children): ein Sprachförderprogramm. Sprachförderung und Sprachtherapie in Schule und Praxis. 1, 45-54.

Gass, S., and Glew, M. (2008). "Second language acquisition and bilingualism," in An Introduction to Bilingualism. Principles and Processes, eds J. Altarriba and R.R. Heredia (New York,NY; London: Lawrence Erlbaum), 265-294.

Genesee, F. (1995). “The Canadian second language immersion program," in Policy and Practice in Bilingual Education: Extending the Foundations, eds O. García and C. Baker (Bristol: Multilingual Mattes), 118-133.

Griffin, G., and Harley, T. A. (1996). List learning of second language vocabulary. Appl. Psycholinguist. 17, 443-460. doi: 10.1017/S01427164000 08195

Karas, M. (2016). "Zum Einfluss unterschiedlicher Einführungskontexte auf die Fast-Mapping-Leistungen von Vorschulkindern mit Deutsch als Zweitsprache," in Frühe Sprachliche und Literale Bildung. Sprache Lernen und Fördern im Kindergarten und Zum Schuleintritt, eds I. Barkow and C. Müller (Tübingen: Narr francke attempo), 11-26.

Kaushanskaya, M., and Marian, V. (2009). The bilingual advantage in novel word learning. Psychon. Bull. Rev. 16, 705-710. doi: 10.3758/PBR.16.4.705

Klein, W., and Dimroth, C. (2003). "Der ungesteuerte Zweitspracherwerb Erwachsener: Ein Überblick über den Forschungsstand," in Qualitätsanforderungen für die Sprachförderung im Rahmen der Integration von Zuwanderern, eds U. Maas and U. Mehlem (Osnabrück: IMIS), 127-161.

Komor, A. (2008). "Semantische Basisqualifikation", in Referenzrahmen zur Altersspezifischen Sprachaneignung -Forschungsgrundlagen, eds K. Ehlich, U. Bredel, and H. H. Reich (Bonn: BMBF Referat Bildungsforschung), 51-76.

Krashen, S. D., and Terrell, T. D. (1983). The Natural Approach: Language Acquisition in the Classroom. San Francisco, CA: Pergamon/Alemany Press.

Kuhs, K. (2008). "Einflussfaktoren auf die schulische L2-Kompetenz von SchülerInnen und Schülern mit Deutsch als Zweitsprache", in Deutsch als Zweitsprache, eds B. Ahrenholz and I. Oomen-Welke (Baltmannsweiler: Schneider Verlag Hohengehren), 395-406.

Langdon, H. W. (2011). "Bilingual language acquisition and learning," in Language Development. Understanding Language Diversity in the Classroom, eds S. Levey and S. Polirstok (Los Angeles, CA; London; New Delhi; Singapore; Washington, DC: SAGE), 245-262.
Leseman, P. P. M. (2000). Bilingual vocabulary development of Turkish preschoolers in the Netherlands. J. Multilingual Multicult. Dev. 21, 93-112. doi: $10.1080 / 01434630008666396$

Meng, K., and Rehbein, J. (2007). Kindliche Kommunikation - Einsprachig und Mehrsprachig. Münster; New York, NY; München; Berlin:Waxmann.

Paradis, M. (2004). A Neurolinguistics Theory of Bilingualism. Philadelphia, PA: John Benjamins.

Peregoy, S. F., and Boyle, O. F. (2008). Reading, Writing, and Learning in ESL: a Resource Book for Teaching K-12 English Learners. 5th Edn, Boston, MA Pearson Education Inc.

Ronjat, J. (1913). Le Développement du Langage Observé Chez un Enfant Bilingue. Paris: Champion.

Schelletter, C., and Ramsey, R. (2010). "Lexical and grammatical comprehension in monolingual and bilingual children", in Bilingual Preschools: Learning and Development, eds K. Kersten, A. Rohde, C. Schelletter, and A. Steinlen (Trier: Wissenschaftlicher Verlag Trier), 101-117.

Schrauf, R. W. (2008). "Bilingualism and Aging," in An Introduction to Bilingualism. Principles and Processes, eds J. Altarriba and R. R. Heredia (New York, NY; London: Lawrence Erlbaum), 105-128.

Steinlen, A., Neils, K., Piske, T., and Trumpp, C. (2010). "SETK 3-5: A developmental language test on German for 3-to-5-year-old children", in Bilingual Preschools: Learning and Development, eds K. Kersten, A. Rohde, C. Schelletter, and A. Steinlen (Trier: Wissenschaftlicher Verlag Trier), 119-135.

Stoll, H. (2012). PROBIMUC-Programme for bi- and Multilingual Children. Bachelor's thesis. Potsdam: University of Potsdam.

Tracy, R. (2008). Wie Kinder Sprachen lernen: Und Wie Wir Sie Dabei Unterstützen Können. Tübingen: Gunter Narr Verlag.

Vygotsky, L. S. (1978). Mind in Society: The Development of Higher Psychological Processes. Cambridge, MA: Harvard University press.

Winsler, A., Díaz, R. M., Espinosa, L., and Rodríguez, J. L. (1999). When learning a second language does not mean losing the first: bilingual language development in low-income, Spanish-speaking children attending bilingual preschool. Child Dev. 70, 349-362.

Zaiser, D. (2005). Musik und Rhythmus in der Sprachförderung. München: DJIVerlag.

Conflict of Interest Statement: The author declares that the research was conducted in the absence of any commercial or financial relationships that could be construed as a potential conflict of interest.

Copyright $\odot 2018$ Festman. This is an open-access article distributed under the terms of the Creative Commons Attribution License (CC BY). The use, distribution or reproduction in other forums is permitted, provided the original author(s) and the copyright owner(s) are credited and that the original publication in this journal is cited, in accordance with accepted academic practice. No use, distribution or reproduction is permitted which does not comply with these terms. 